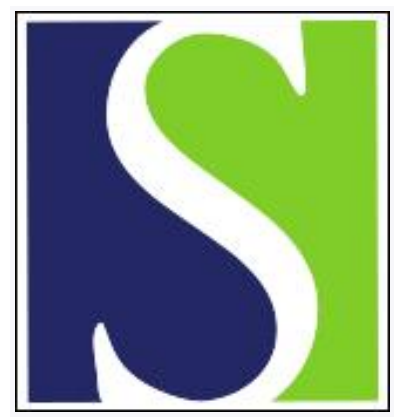

Scand J Work Environ Health 2019;45(2):114-125

https://doi.org/10.5271/sjweh.3772

Published online: 29 Oct 2018, Issue date: 01 Mar 2019

The contribution of work and lifestyle factors to socioeconomic inequalities in self-rated health - a systematic review

by Dieker ACM, IJzelenberg W, Proper KI, Burdorf A, Ket JCF, van der Beek Al, Hulsegge $G$

This study is the first systematic review on the contribution of work and lifestyle factors to socioeconomic inequalities in perceived health among workers. Work and lifestyle factors partly explained socioeconomic health inequalities. This has important implications for public and occupational health policy as it emphasizes to focus on both work and lifestyle factors to reduce socioeconomic inequalities in perceived health.

Affiliation: Amsterdam UMC, Vrije Universiteit Amsterdam, Department of Public and Occupational Health, Amsterdam Public Health Research Institute, Van der Boechorststraat 7, NL-1081 BT Amsterdam, The Netherlands. g.hulsegge@vumc.nl

Refers to the following text of the Journal: 2006;32(6):443-462

The following articles refer to this text: 2019;45(4):321-323; 2020;46(1):77-84; 2021;47(2):127-135; 2021;47(8):561-564; 2022;48(7):569-578

Key terms: health inequality; lifestyle; lifestyle factor; review; self-rated health; socioeconomic; socioeconomic factor; socioeconomic inequality; socioeconomic status; systematic review; work factor

This article in PubMed: www.ncbi.nlm.nih.gov/pubmed/30370911

\title{
Additional material
}

Please note that there is additional material available belonging to this article on the Scandinavian Journal of Work, Environment \& Health -website.

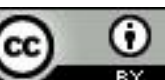




\title{
The contribution of work and lifestyle factors to socioeconomic inequalities in self-rated health - a systematic review
}

\author{
by Amy CM Dieker, MSc, ${ }^{1}$ Wilhelmina IJzelenberg, PhD, ${ }^{2}$ Karin I Proper, PhD, ${ }^{3}$ Alex Burdorf, PhD, ${ }^{4}$ Johannes CF Ket, MSc, ${ }^{5}$ \\ Allard J van der Beek, PhD, ${ }^{1}$ Gerben Hulsegge, PhD ${ }^{1}$
}

\begin{abstract}
Dieker ACM, IJzelenberg W, Proper KI, Burdorf A, Ket JCF, van der Beek AJ, Hulsegge G. The contribution of work and lifestyle factors to socioeconomic inequalities in self-rated health - a systematic review. Scand J Work Environ Health. 2019;45(2):114-125. doi:10.5271/sjweh.3772
\end{abstract}

\begin{abstract}
Objective This study aimed to systematically review the literature on the contribution of work and lifestyle factors to socioeconomic inequalities in self-rated health among workers.

Methods A search for cross-sectional and longitudinal studies assessing the contribution of work and/or lifestyle factors to socioeconomic inequalities in self-rated health among workers was performed in PubMed, PsycINFO, and Web of Science in March 2017. Two independent reviewers performed eligibility and risk of bias assessment. The median change in odds ratio between models without and with adjustment for work or lifestyle factors across studies was calculated to quantify the contribution of work and lifestyle factors to health inequalities. A best-evidence synthesis was performed.
\end{abstract}

Results Of those reviewed, 3 high-quality longitudinal and 17 cross-sectional studies consistently reported work factors to explain part (about one-third) of the socioeconomic health inequalities among workers (grade: strong evidence). Most studies separately investigated physical and psychosocial work factors. In contrast with the 12 cross-sectional studies, 2 longitudinal studies reported no separate contribution of physical workload and physical work environment to health inequalities. Regarding psychosocial work factors, lack of job resources (eg, less autonomy) seemed to contribute to health inequalities, whereas job demands (eg, job overload) might not. Furthermore, 2 longitudinal and 4 cross-sectional studies showed that lifestyle factors explain part (about one-fifth) of the health inequalities (grade: strong evidence)

Conclusions The large contribution of work factors to socioeconomic health inequalities emphasizes the need for future longitudinal studies to assess which specific work factors contribute to health inequalities.

Key terms health inequality; perceived health; socioeconomic factor; socioeconomic status; work factor; worker.

People with a low socioeconomic status (SES) have higher mortality rates and worse health than people with a high SES (1-3). For example, in the Netherlands people with a low SES live 16-19 years less in good self-rated health than those with a high SES (4). To narrow the gap of socioeconomic health inequalities, further insight into the determinants of these health inequalities is needed.

Several factors explain the socioeconomic inequalities in health, such as behavior and the living and working environment $(5,6)$. Two main hypotheses for the role of lifestyle behaviors and the living and working environment in explaining socioeconomic inequalities in health exist $(6,7)$ : (i) people with a low SES have a less healthy lifestyle and live and work in more disadvantaged conditions than people with a high SES (mediation effect) and (ii) the effects of unhealthy lifestyle and living and working conditions on health is larger in those with a low SES (moderating effect). One systematic review focused on the mediating effects and found that material factors, such as housing and physical work fac-

1 Amsterdam UMC, Vrije Universiteit Amsterdam, Department of Public and Occupational Health, Amsterdam Public Health Research Institute, Amsterdam, The Netherlands.

2 Department of Health Sciences, Faculty of Earth and Life Sciences, VU University Amsterdam, Amsterdam Public Health Research Institute, Amsterdam, The Netherlands.

3 Centre for Nutrition, Prevention and Health Services, National Institute for Public Health and the Environment, Bilthoven, The Netherlands.

4 Department of Public Health, Erasmus University Medical Center, Rotterdam, The Netherlands.

5 Medical Library, VU University Amsterdam, Amsterdam, The Netherlands.

Correspondence to: Gerben Hulsegge, Amsterdam UMC, Vrije Universiteit Amsterdam, Department of Public and Occupational Health, Amsterdam Public Health Research Institute, Van der Boechorststraat 7, NL-1081 BT Amsterdam, The Netherlands [E-mail: g.hulsegge@vumc.nl]. 
tors, explained the largest part of the relation between socioeconomic position (ie, income, occupational class, and education) and self-rated health (5). This was followed by behavioral factors, such as smoking and physical inactivity, and psychosocial factors, such as lack of social support. That review focused on the general population and did not extensively study work factors, ie, they only included one study that investigated working conditions. Another review concluded that there was moderate evidence that work factors mediate the relation between income, occupational class, and education and health outcomes (eg, cardiovascular disease, self-rated health, low-back pain) (6). However, this review did not make a clear distinction between health outcomes and only included three studies on self-rated health. They also did not investigate the role of lifestyle in the relation between SES and health, while lifestyle factors strongly intertwine with work factors. Workers with unfavorable working conditions are more likely to have an unhealthy lifestyle $(8,9)$.

In sum, previous studies indicate that work and lifestyle factors may explain part of the relation between SES and self-rated health among workers, but a systematic synthesis of the literature on the relative contribution of work and lifestyle factors for the explanation of socioeconomic inequalities in self-rated health is currently lacking. This synthesis should give direction to prevention to reduce the socioeconomic inequalities in health among workers. We focused on self-rated health as work factors seem to particularly contribute to socioeconomic inequalities in self-rated health (6). Moreover, self-rated health is a strong predictor of morbidity and mortality (10-12). Therefore, we aimed to systematically review the literature to quantify the relative contribution of work and lifestyle factors to socioeconomic inequalities in self-rated health within the working population.

\section{Methods}

This study is being reported according to the PRISMA statement and the protocol was registered on PROSPERO with registration number CRD42017065026.

\section{Inclusion and exclusion criteria}

To be included in the present review, studies had to meet the following eligibility criteria: (i) In a pretest search, we found very few longitudinal studies investigating the contribution of work and lifestyle factors to inequalities in self-rated health. Therefore, studies with either a longitudinal or cross-sectional design were included; (ii) the study had to include a non-patient population of persons who were active on the labor market; (iii) SES had to be measured by income, occupation, or educational level; (iv) the outcome had to be self-rated health; (v) the study had to investigate the mediating or moderating effect of work or lifestyle factors to the relation between SES and self-rated health.

We distinguished psychosocial factors (eg, job insecurity, decision latitude, and social support at work) and physical work factors, which we divided into physical workload (eg, biomechanical, physical strain) and physical work environment (eg, chemical and biological hazards), as previous studies (2,13-24). Physical inactivity in leisure time, unhealthy diet, smoking, excessive drinking behavior, being overweight and sedentary behavior were considered as unhealthy lifestyle factors. Workers were defined as people who are active on the labor market as employees or self-employed. In the fulltext screening phase, studies written in another language than English, French, German or Dutch were excluded.

\section{Search strategy}

PubMed, Ebsco/PsycINFO and Clarivate Analytics/Web of Science were searched from inception up to March 31,2017 . The following terms were used (including synonyms and closely related words) as index terms or freetext words in two search strings that were combined: (i) work factors (eg, "job demands") and socioeconomic position (eg, "social class") and self-rated health (eg, "perceived health") and (ii) "workers" or "occupational groups" and "lifestyle" and socioeconomic position and self-rated health; excluding "children" or "reviews" or "case reports" or "clinical trials" for both search strings (see supplementary information for the full search strategy). "Workers" was added to the second search string since we were only interested in the mediating or moderating role of lifestyle factors to socioeconomic inequalities in self-rated health among workers. Included studies were also checked for relevant references.

\section{Selection of studies}

Two review authors independently screened the titles and abstracts from the search results. Potentially relevant studies were obtained in full text and independently assessed for inclusion. Disagreements were resolved through discussion. A third review author was contacted if an arbiter was necessary.

\section{Data extraction}

Using a standardized form the following data were extracted: study characteristics, participant characteristics, type of lifestyle and/or work factors, measurement of outcome (self-rated health), measurement of SES, 
statistical analyses, and results. Data extraction was executed by one reviewer, after which a second reviewer checked the statistical analyses and results.

\section{Assessment of risk of bias}

For each of the included studies, two reviewers independently performed a risk of bias assessment and discussed possible discrepancies in the risk of bias assessment. If agreement could not be reached, a third reviewer was consulted in order to reach consensus. The risk of bias of the included studies was assessed by a predefined checklist, as used in previous studies (25-27). The criteria list addressed informativeness (eg, adequate description of population and recruitment methods), validity, and precision (eg, health outcome and work factors measured with validated questionnaires, appropriate statistical method used). The criteria were scored as "low risk" (+), "high risk" (-) or "unclear risk" (?). Studies that scored at least $60 \%$ "low risk" items were considered to be of "high quality" (25-27). Authors were contacted for more information if items could not be scored.

\section{Relative contribution of work and lifestyle factors}

The relative contribution of work and lifestyle factors to socioeconomic inequalities in self-rated health was calculated where possible. This was done by calculating the percentage change in odds ratios (OR) of poor self-rated health in the lowest compared to highest SES between the model without adjustment (model 1) and the model with adjustment (model 2) for work or lifestyle factors. This was done by the following formula $(13,19,28)$ :

[(OR model 1- OR model 2) / (OR model $1-1)] \times 100$

\section{Best-evidence synthesis}

It was not possible to perform a meta-analysis due to heterogeneity in designs, statistical methods, measurement of work factors, lifestyle factors, and SES across included studies. Therefore, a best-evidence synthesis was performed to synthesize the results. As in previous studies $(26,29,30)$, the following levels of evidence were defined: (i) strong evidence: consistent findings in two or more high-quality longitudinal studies; (ii) moderate evidence: consistent findings in one high-quality longitudinal study and in at least two high-quality cross-sectional studies; (iii) limited evidence: consistent findings in one single longitudinal study, or consistent findings in at least two cross-sectional studies; (iv) conflicting evidence: non-consistent findings.

In case of $\geq 2$ high-quality longitudinal studies, crosssectional studies were disregarded in the best-evidence synthesis. Results were considered to be consistent when there was a contribution of $\geq 10 \%$ of work or lifestyle factors to socioeconomic inequalities in self-rated health, the same $10 \%$ change in effect estimate used to identify confounding $(31,32)$. With regard to work factors, we included studies in the primary best-evidence synthesis that investigated the combined contribution of physical and psychosocial work factors. In addition, we synthesized the studies that separately investigated physical or psychosocial work factors. In studies that assessed multiple work factors separately and not combined, we only used the work factor that contributed the most to socioeconomic health inequalities in the bestevidence synthesis.

To provide an indication of the relative contribution of work and lifestyle factors to socioeconomic inequalities, we calculated the median [and interquartile range (IQR)] contribution across all studies. If a study presented only stratified results by gender, we used the average contribution in men and women in calculating the median contribution across studies to give each study the same weight. If studies report their results, separately, for different definitions of SES, we also used the average contribution of the stratified results by SES to calculate the median contribution across studies. As education, income, and occupational class may relate to different causal processes (33), we also calculated the median contribution for each indicator of SES separately.

\section{Sensitivity analysis}

To assess the robustness of the findings in the bestevidence synthesis, a sensitivity analysis was performed. In this analysis, "high-quality" was attributed to studies with a low risk of bias score of $\geq 75 \%$ instead of $\geq 60 \%$. To assess the impact of the accuracy of measurement of the work factors to the results, we calculated the median contribution for studies using questionnaires evaluated in validation studies (eg, job content questionnaire) with studies using other questionnaires. In addition, we compared studies that measured $<4$ different domains of work and/or lifestyle with studies that measured $\geq 4$ domains.

\section{Results}

\section{Search and selection}

After removing duplicates, the literature search resulted in 6558 references. After two reviewers screened title and abstract, 69 references were selected to read in fulltext and 42 references were excluded since they did not meet the eligibility criteria. This resulted in 27 studies being included in this review (figure 1). No additional papers were found by reference screening. All studies 
investigated the mediating effect, and none the moderating effect, of work and lifestyle factors on the relation between SES and self-rated health.

\section{Characteristics of included studies}

Of the selected studies, 25 included a general sample of the workforce, 1 included only office workers from civil service departments (34), and 1 included only workers from the industry sector (supplemental table S1, www. sjweh.fi/show_abstract.php?abstract_id=3772) (14).

A longitudinal design was applied in 6 studies and 21 had a cross-sectional design. SES was measured by occupation in 20 studies, by education in 8 and by income in 5; 2 studies combined occupation and education into one measure of SES, and 4 used multiple measures for SES.

\section{Risk of bias of included studies}

The risk of bias assessment resulted in all 27 studies being of high-quality. The two reviewers disagreed on 13 items (5\%), which the third reviewer resolved. The most frequent limitations of the studies were the lack of using, or lack of stating the use of, a validated questionnaire to assess work factors, $<80 \%$ of the invited people participated, and an insufficient description of the study sample (table 1).

\section{Outcome and analysis}

As table 1 shows, 16 studies assessed self-rated health using the validated question of the SF-36 questionnaire;. 11 assessed self-rated health using a comparable question, but it was unclear whether this was the exact same question from the SF-36 questionnaire, or slightly different answer options were included (17, $35,36)$. Logistic regression analysis was used in 23 studies, while 1 applied path analysis (37), 1 a sibling resemblance model (38), and 1 a dynamic panel correlated random effects probability model (21). All studies adjusted the analysis for age and gender or stratified by gender except for the study of Brand et al (38). Only 2 studies additionally adjusted the baseline model for lifestyle factors (ie, body mass index, physical activity and smoking) $(38,39)$.

\section{Relation between SES and self-rated health}

In all studies, workers in the lowest SES had a statistically significantly higher risk of poor self-rated health than workers in the highest SES for at least one measure of SES (range OR 1.11-7.69). In 4 studies this relation was not statistically significant for $\geq 1$ of the SES measures and/or genders $(15,39-41)$, eg, the association between SES and self-rated health was statistically significant among men but not women $(15,41)$.

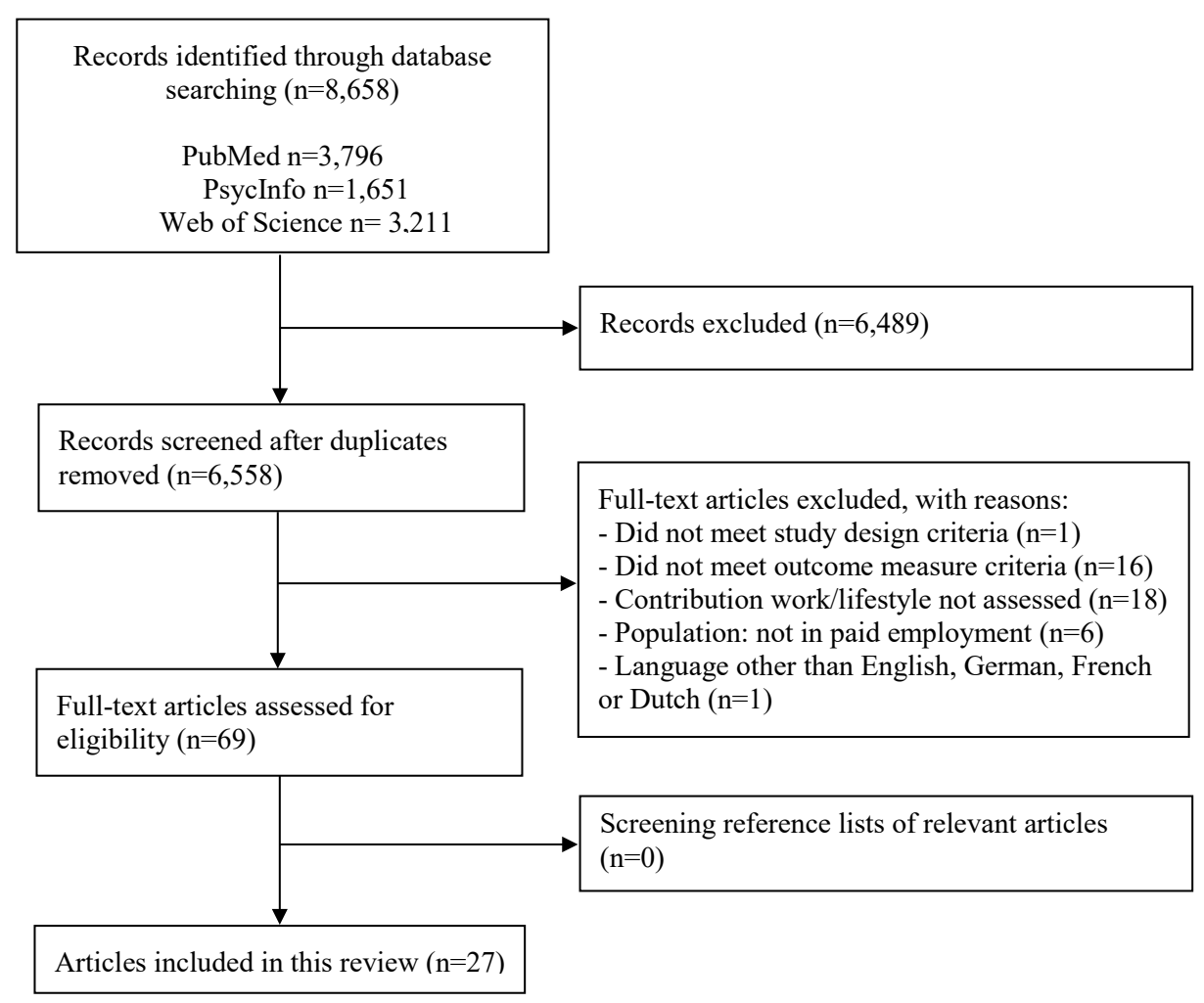

Figure 1. Flowchart of selected studies. 
Table 1. Summary of Risk of Bias assessment. [+ = low risk; - = high risk; ? = unclear risk. Last six items were applicable only to longitudinal studies (highlighted in bold).]

\begin{tabular}{|c|c|c|c|c|c|c|c|c|c|c|c|c|c|c|c|c|c|c|c|c|c|c|c|c|c|c|c|}
\hline \multirow{2}{*}{$\begin{array}{l}\text { Criteria of risk of bias } \\
\text { assessment }^{\text {a }}\end{array}$} & \multicolumn{27}{|c|}{ Study (risk of bias score) } \\
\hline & 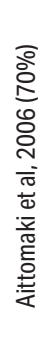 & 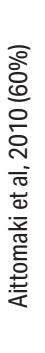 & 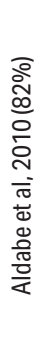 & 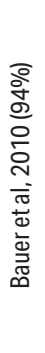 & 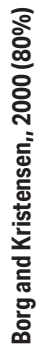 & 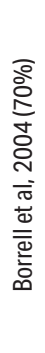 & 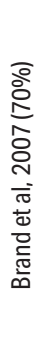 & 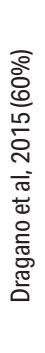 & 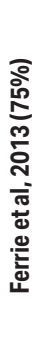 & 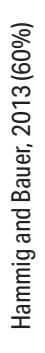 & 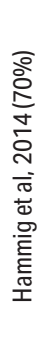 & 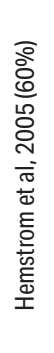 & 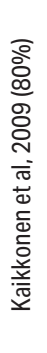 & 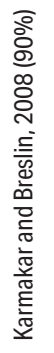 & 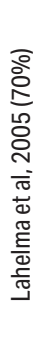 & 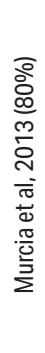 & 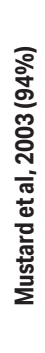 & 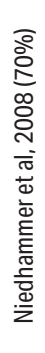 & 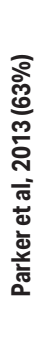 & 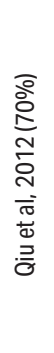 & 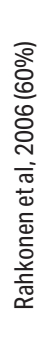 & 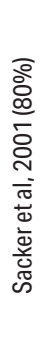 & 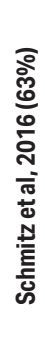 & 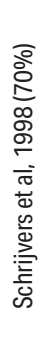 & 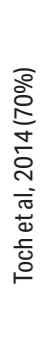 & 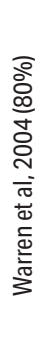 & 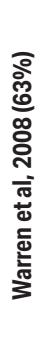 \\
\hline $\begin{array}{l}\text { Adequate description of } \\
\text { source population }\end{array}$ & + & + & + & + & - & + & + & + & + & + & + & + & + & + & + & + & + & + & + & + & + & + & - & + & + & + & + \\
\hline $\begin{array}{l}\text { Adequate description of sam- } \\
\text { pling frame and recruitment }\end{array}$ & + & + & + & + & + & + & + & + & + & + & + & + & + & + & + & + & + & + & - & + & - & - & - & + & + & + & + \\
\hline $\begin{array}{l}\text { Response rate at least } 80 \% \text { or } \\
\text { non-selective nonresponse }\end{array}$ & - & - & - & - & + & - & + & - & - & - & - & - & - & + & - & + & + & + & + & - & - & - & + & - & - & + & $?$ \\
\hline $\begin{array}{l}\text { Adequate description of study } \\
\text { sample }\end{array}$ & - & - & + & + & - & - & - & - & - & + & + & + & - & + & - & + & + & - & + & + & - & + & - & - & - & - & - \\
\hline $\begin{array}{l}\text { Work factors were measured } \\
\text { with a valid questionnaire }\end{array}$ & - & - & - & + & - & - & - & - & + & - & - & - & + & - & - & - & + & - & - & - & - & + & - & - & - & - & - \\
\hline $\begin{array}{l}\text { Perceived health measured } \\
\text { with a validated questionnaire }\end{array}$ & + & - & + & + & + & + & + & - & + & + & - & - & + & + & + & - & - & - & - & - & + & + & - & + & + & + & - \\
\hline $\begin{array}{l}\text { The statistical model used was } \\
\text { appropriate }\end{array}$ & + & + & + & + & + & + & + & + & + & + & + & + & + & + & + & + & + & + & + & + & + & + & + & + & + & + & + \\
\hline $\begin{array}{l}\text { Important confounders (age, } \\
\text { gender) were identified and } \\
\text { adjusted for }\end{array}$ & + & + & + & + & + & + & - & + & + & + & + & + & + & + & + & + & + & + & + & + & + & + & + & + & + & + & + \\
\hline $\begin{array}{l}\text { Number of participants was } \\
\geq 10 \text { times the number of inde- } \\
\text { pendent variables }\end{array}$ & + & + & + & + & + & + & + & + & - & + & + & + & + & + & + & + & + & + & + & + & + & + & + & + & + & + & + \\
\hline $\begin{array}{l}\text { Presentation of point es- } \\
\text { timates and measures of } \\
\text { variability }\end{array}$ & + & + & + & + & + & + & + & + & + & - & + & - & + & + & + & + & + & + & - & + & + & + & + & + & + & + & + \\
\hline $\begin{array}{l}\text { Provision of the exact number at } \\
\text { each follow-up measurement }\end{array}$ & & & & & + & & & & - & & & & & & & & + & & + & & & & - & & & & - \\
\hline $\begin{array}{l}\text { Provision of the exact informa- } \\
\text { tion on follow-up duration }\end{array}$ & & & & & + & & & & + & & & & & & & & + & & + & & & & + & & & & + \\
\hline $\begin{array}{l}\text { Response at follow-up ( } 80 \% \\
\text { short-term, } 70 \% \text { long-term) }\end{array}$ & & & & & + & & & & + & & & & & & & & + & & - & & & & + & & & & + \\
\hline $\begin{array}{l}\text { Information on not selective } \\
\text { nonresponse at follow-up }\end{array}$ & & & & & + & & & & + & & & & & & & & + & & + & & & & + & & & & - \\
\hline $\begin{array}{l}\text { Socioeconomic position was } \\
\text { assessed prior to measure- } \\
\text { ment of perceived health }\end{array}$ & & & & & + & & & & + & & & & & & & & + & & + & & & & + & & & & + \\
\hline $\begin{array}{l}\text { Work-related factors were as- } \\
\text { sessed prior to measurement } \\
\text { of perceived health }\end{array}$ & & & & & + & & & & + & & & & & & & & + & & + & & & & + & & & & + \\
\hline
\end{tabular}

\section{The contribution of work factors}

Except for women in the study of Warren et al (41), all 3 longitudinal studies $(21,41,42)$ showed that physical and psychosocial work factors combined contributed to socioeconomic inequalities in self-rated health. All of these studies included a combination of physical demands (eg, heavy lifting), hazards (eg, noise exposure and safety risks), and psychosocial factors (eg, work pressure and job insecurity). Of the 16 cross-sectional studies, 15 also consistently reported that work factors contributed to these health inequalities $(2,13-19,22-24,36,38-40$,
43). Work factors explained over one-third of the health inequalities: median contribution in all studies of $45 \%$ (IQR 30-58\%), in longitudinal studies of 26\% (range $14-38 \%$ ), and in cross-sectional studies of $45 \%$ (IQR $31-60 \%$ ) (table 2). Work factors explained a larger part of the health inequalities in the studies that did not adjust the primary model for lifestyle factors (median $50 \%$, IQR 40-58\%) compared to studies that adjusted for lifestyle factors (median 29\%, IQR 24-32) $(15,16,38,39,41)$. Work and lifestyle factors contributed to health inequalities irrespective of the measurement of SES (ie, income, 
Table 2. The contribution of work and lifestyle factors to socioeconomic differences in self-rated health, stratified by education, occupational class, and income as measures of socioeconomic position. [LCS=Iongitudinal cohort study; $C S=$ cross-sectional study; $S E S=$ socioeconomic status; IQR=interquartile range; $N=$ number; $N A=$ not applicable because too few studies were available to calculate the median and/or IQR.]

\begin{tabular}{|c|c|c|c|c|c|c|c|c|}
\hline & \multicolumn{2}{|c|}{$\begin{array}{c}\text { Physical and } \\
\text { psychosocial combined }\end{array}$} & \multicolumn{2}{|c|}{$\begin{array}{l}\text { Physical } \\
\text { work factors }\end{array}$} & \multicolumn{2}{|c|}{$\begin{array}{l}\text { Psychosocial } \\
\text { work factors }\end{array}$} & \multicolumn{2}{|c|}{ Lifestyle } \\
\hline & LCS & CS & LCS & CS & LCS & CS & LCS & CS \\
\hline \multicolumn{9}{|c|}{ SES measures combined } \\
\hline Median (\%) & 26 & 45 & 6 & 36 & 8 & 33 & 23 & 21 \\
\hline IQR (\%) & NA & $31-60$ & NA & $27-55$ & $-1-9$ & $21-40$ & NA & $15-28$ \\
\hline Studies (N) & 2 & 16 & 1 & 11 & 3 & 14 & 2 & 4 \\
\hline \multicolumn{9}{|l|}{ Education } \\
\hline Median (\%) & 3 & 29 & 6 & 53 & -7 & 36 & NA & 21 \\
\hline IQR (\%) & NA & $24-50$ & NA & NA & NA & $17-48$ & NA & $30-44$ \\
\hline Studies (N) & 1 & 3 & 1 & 1 & 1 & 3 & 0 & 3 \\
\hline \multicolumn{9}{|l|}{ Occupation } \\
\hline Median (\%) & NA & 54 & 6 & 36 & -3 & 38 & NA & 17 \\
\hline IQR (\%) & NA & $39-66$ & NA & $30-56$ & NA & $28-48$ & NA & $17-17$ \\
\hline Studies (N) & 0 & 12 & 1 & 10 & 2 & 11 & 0 & 3 \\
\hline \multicolumn{9}{|l|}{ Income } \\
\hline Median (\%) & NA & 24 & NA & 24 & NA & 24 & NA & NA \\
\hline IQR (\%) & NA & $21-41$ & NA & NA & NA & NA & NA & NA \\
\hline Studies (N) & 0 & 3 & 0 & 1 & 0 & 1 & 0 & 0 \\
\hline \multicolumn{9}{|c|}{ Education and occupation combined } \\
\hline Median (\%) & NA & 58 & NA & NA & NA & -100 & NA & NA \\
\hline IQR (\%) & NA & NA & NA & NA & NA & NA & NA & NA \\
\hline Studies (N) & 0 & 1 & 0 & 0 & 0 & 1 & 0 & 0 \\
\hline
\end{tabular}

education, or occupational class) (figure 2). Based on cross-sectional studies, the contribution of work factors (physical and psychosocial combined) to health inequalities seems to be larger in studies in which SES was measured by occupational class (54\%) compared to education $(29 \%)$ and income $(45 \%)$ (table 2). This was not the case for studies investigating physical work factors only (contribution occupational class: $36 \%$, education: $53 \%$, and income: $36 \%$ ).

With regard to the separate contribution of physical work factors to health inequalities, the longitudinal study of Parker et al (20) used a single question to measure exposure to gas, dust, smoke, noise and heavy lifting (20). This study showed that these factors explained only $6 \%$ of the socioeconomic inequalities in self-rated health after a follow-up of 23 years. Another longitudinal study that measured physical workload (eg, climbing and lifting) and physical work environment (eg, noise and contaminants) using a job exposure matrix reported that these physical work factors did not contribute to the health inequalities (21). In contrast, all cross-sectional studies showed a contribution of physical work factors (median contribution 51\%, IQR 31-60\%) (2, 13, 15-19, 22-24, 44). Six cross-sectional studies (17-19, 23, 24, 44 ) investigated the contribution of physical workload and three cross-sectional studies $(17,19,24)$ the contribution of physical work environment. Based on these studies, the contribution of physical workload (median $40 \%$, range 16-54) to health inequalities seems larger than the contribution of physical work environment (median 14\%, range 13-45).

Four longitudinal studies investigated the separate contribution of psychosocial work factors to health inequalities, and reported inconsistent findings (20, 21, 34, 35). Supportive management, decision latitude and job control were significant contributors in one longitudinal study (21). Mustard et al (33) showed that unfavorable job demand-control explained $40 \%$ of the health inequalities among men but not women (35). Ferrie et al (34) showed that job insecurity contributed $8 \%$ to health inequalities (34). Parker et al (20) reported an opposite effect of mentally taxing, stressful, repetitious, monotonous, or mentally exhausting work demands as contributor to health inequalities after a 23 -year followup (20). Of the 14 cross-sectional studies, 12 showed that psychosocial work factors contributed to health inequalities $(2,13,15-17,19,22-24,37,45,46)$. The median contribution of psychosocial work factors was $8 \%$ (IQR $-1-9 \%$ ) in longitudinal studies and 33\% (IQR $21-40 \%)$ in cross-sectional studies.

\section{The contribution of lifestyle factors}

The longitudinal study of Borg \& Kristensen (42) showed that $17 \%$ of the socioeconomic health inequalities were explained by smoking and body weight. Mustard et al (35) reported that alcohol consumption, smoking and physical inactivity explained $29 \%$ of the inequalities. This was also found in the majority of the cross-sectional studies, of which 3 reported a contribution of lifestyle factors $(37,38,46)-1$ only in men and not women (40) while another did not observe a contribution of lifestyle factors to the inequalities (15). When considering all studies that investigated lifestyle 

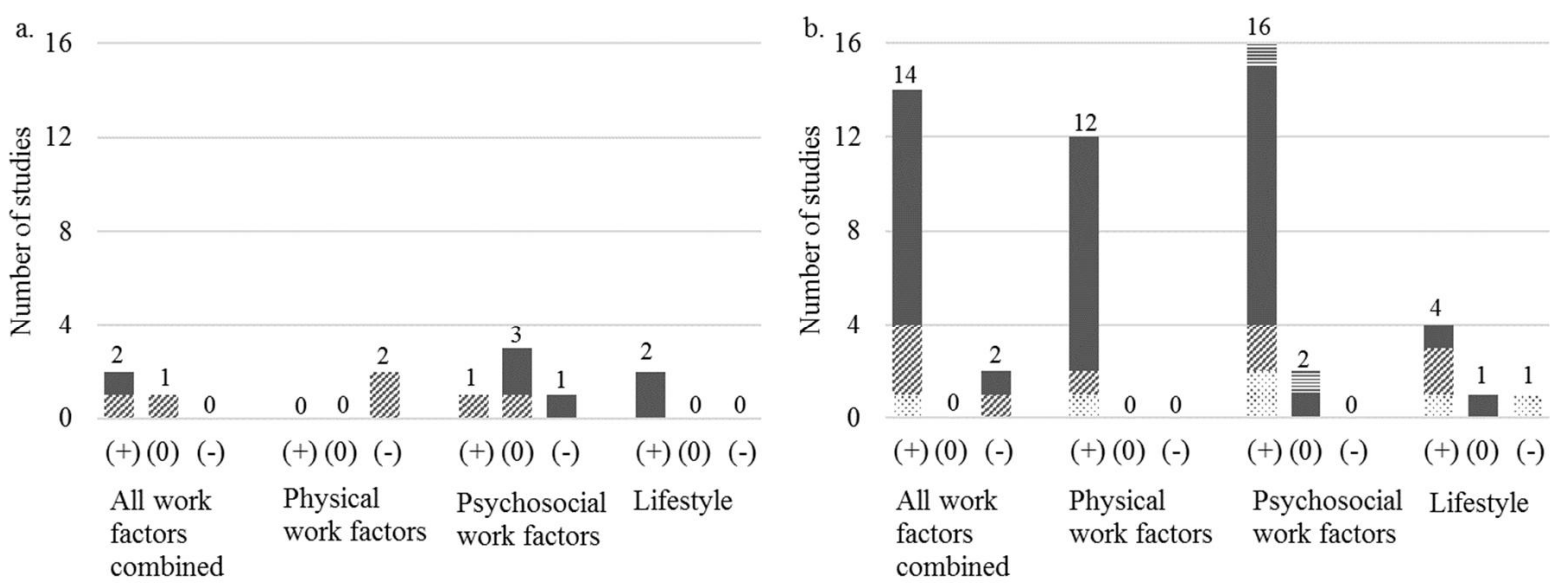

Figure 2. The number of longitudinal (a) and cross-sectional (b) studies showing a contribution (+), no contribution (0), and opposite effect (-) of work and lifestyle factors to health inequalities. Note: studies measured socioeconomic position with income (dotted bars), education (bars with diagonal lines), occupational class (filled bars), and a combined measure of SEP (horizontal lines). Studies were counted more than once if they measured socioeconomic position with more than one socioeconomic position proxy.

factors, lifestyle explained about one-fifth (median $21 \%$, IQR $18-27 \%$ ) of the health inequalities, while work factors explained 2.5 times as much (median $54 \%$, IQR $45-62 \%)$. The analysis for work factors was adjusted in 2 studies $(40,42): 1$ observed that lifestyle still explained $19 \%$ of health inequalities (42), while, in the other, lifestyle did not explain the inequalities at all (0\%) (40).

\section{Best-evidence synthesis}

Based on 3 high-quality longitudinal studies, it was concluded that there was strong evidence available that physical and psychosocial work factors combined contribute to socioeconomic inequalities in self-rated health (table 3 and figure 2) $(21,41,42)$. Based on the 2 longitudinal studies $(20,21)$, there was no evidence that physical work factors (ie, physical workload and physical work environment) separately contribute to health inequalities. Of the 4 longitudinal studies, 2 observed that psychosocial work factors separately contribute to health inequalities $(21,35)$, ie, conflicting evidence for the role of psychosocial factors in health inequalities. Finally, based on 2 longitudinal studies, there was strong evidence that lifestyle factors contribute to the socioeconomic differences in self-rated health among workers $(35,42)$.

\section{Sensitivity analysis}

When considering studies with a risk of bias score of $\geq 75 \%$ instead of $\geq 60 \%$ as "high-quality", the evidence for psychosocial and physical work factors combined downgraded from strong to moderate evidence, as 2 longitudinal studies had a risk of bias score between $60-75 \%(21,41)$. The level of evidence for physical work factors upgraded to limited evidence, and the level of evidence for psychosocial work factors did not change. The contribution of work factors was larger in studies that used validated questionnaires to assess work factors $(62 \%)$ than those that did not use validated questionnaires (39\%). In addition, the contribution of work and lifestyle to health inequalities was larger in the cross-sectional studies that measured $\geq 4$ domains of work $(53 \%)$ and lifestyle (35\%) compared to $<4$ domains ( $34 \%$ and $10 \%$, respectively).

\section{Discussion}

We found strong evidence that physical and psychosocial work factors combined explain part (approximately one-third) of the socioeconomic inequalities in selfrated health. The studies also showed work factors to contribute to these health inequalities irrespective of lifestyle behaviors. Due to a limited number of longitudinal studies and heterogeneous findings across studies, we found no clear evidence which specific work factors contributed to the health inequalities. However, crosssectional studies consistently reported that both physical and psychosocial work factors explained part of the differences in self-rated health by education, income, and occupational class. Finally, we found strong evidence 
Table 3. Best-evidence synthesis of the contribution of work and lifestyle factors to the relation between socioeconomic position and self-rated health. [Longitudinal studies are highlighted in bold.]

\begin{tabular}{|c|c|c|c|c|}
\hline & $+a$ & $0^{b}$ & $-c$ & Level of evidence \\
\hline $\begin{array}{l}\text { Physical and } \\
\text { psychosocial } \\
\text { work factors } \\
\text { combined }\end{array}$ & $\begin{array}{l}\text { Aldabe et al, } 2011 \text { (13); Aittomaki, } 2010 \text { (40); Bauer et al, } 2009 \text { (2); Borg } \\
\text { and Kristensen, } 2000 \text { (42); Borrell et al, } 2004 \text { (43); Brand et al, } 2007 \\
\text { (38); Dragano et al, } 2015 \text { (36); Hammig et al, } 2014 \text { (15); Hemstrom et al, } \\
2005 \text { (16); Kaikkonen et al, } 2009 \text { (17); Lahelma et al, } 2005 \text { (women) (18); } \\
\text { Murcia et al, } 2013 \text { (24); Niedhammer et al, } 2008 \text { (19); Schrijvers et al, } \\
\text { 1998 (22); Schmitz, } 2016 \text { (21); Toch et al, 2014 (23); Warren et al, } 2004 \\
\text { (39); Warren et al, } 2008 \text { (men education) (41) }\end{array}$ & $\begin{array}{l}\text { Lahelma et al, } 2005 \text { (men) (18); } \\
\text { Hammig and Bauer, } 2013 \text { (14) }\end{array}$ & $\begin{array}{l}\text { Warren et al, } 2008 \\
\text { (women education) } \\
\text { (41) }\end{array}$ & Strong \\
\hline $\begin{array}{l}\text { Physical work- } \\
\text { load and } \\
\text { physical work } \\
\text { environment }\end{array}$ & $\begin{array}{l}\text { Aldabe et al, } 2011 \text { (13); Aittomaki et al, } 2006 \text { (44); Bauer et al, } 2009 \text { (2); } \\
\text { Hammig et al, } 2014 \text { (15); Hemstrom, } 2005 \text { (women) (16); Kaikkonen et al, } \\
2009 \text { (17); Lahelma et al, } 2005 \text { (18); Murcia et al, } 2013 \text { (24); Niedhammer } \\
\text { et al, } 2008 \text { (19); Schrijvers et al, } 1998 \text { (22); Toch et al, } 2014 \text { (23) }\end{array}$ & $\begin{array}{l}\text { Hemstrom, } 2005 \text { (men) (16); } \\
\text { Parker et al, } 2013(20) ; \\
\text { Schmitz, } 2016(21)\end{array}$ & & None \\
\hline $\begin{array}{l}\text { Psychosocial } \\
\text { work factors }\end{array}$ & $\begin{array}{l}\text { Aldabe et al, } 2011 \text { (13); Bauer et al, } 2009 \text { (2); Hammig et al, } 2014 \text { (15); } \\
\text { Hemstrom, } 2005 \text { (16); Kaikkonen et al, } 2009 \text { (17); Karmakar and Breslin, } \\
2008 \text { (46); Murcia et al, } 2013 \text { (24); Niedhammer et al, } 2008 \text { (19); Mustard } \\
\text { et al, } 2003 \text { (men) (35); Schrijvers et al, } 1998 \text { (22); Toch et al, } 2014 \text { (23); } \\
\text { Rahkonen et al, } 2005 \text { (45); Sacker et al, } 2001 \text { (37); Schmitz, } 2016 \text { (21) }\end{array}$ & $\begin{array}{l}\text { Parker et al, } 2013 \text { (education) } \\
\text { (20); Ferrie et al, } 2003 \text { (34); } \\
\text { Mustard et al, } 2003 \text { (women) } \\
\text { (35); Qiu et al, } 2012 \text { (women) } \\
\text { (52) }\end{array}$ & $\begin{array}{l}\text { Hammig and Bauer, } \\
2013 \text { (14); Lahelma et } \\
\text { al, } 2005 \text { (18); Parker } \\
\text { et al, } 2013 \text { (occupa- } \\
\text { tion) (20); Qiu et al, } \\
2012 \text { (men) (52) }\end{array}$ & Conflicting \\
\hline $\begin{array}{l}\text { Lifestyle } \\
\text { factors }\end{array}$ & $\begin{array}{l}\text { Karmakar and Breslin, } 2008 \text { (46); Mustard et al, } 2003 \text { (35); Borg and } \\
\text { Kristensen, } 2000 \text { (42); Brand et al, } 2007 \text { (38); Sacker et al, } 2001 \text { (37); } \\
\text { Hammig et al, } 2014 \text { (education, occupational class men) (15) }\end{array}$ & $\begin{array}{l}\text { Aittomaki et al, } 2010 \text { (40); } \\
\text { Hammig et al, } 2014 \text { (occupa- } \\
\text { tional class, women) (15) }\end{array}$ & & Strong \\
\hline
\end{tabular}

that lifestyle factors explained part (approximately one-fifth) of the relation between SES and self-rated health, and that work factors contribute at least as much to inequalities in self-rated health as lifestyle factors.

To our knowledge, this review is the first to assess the relative contribution of work and lifestyle factors to socioeconomic inequalities in self-rated health within the working population. A previous systematic review suggested that material factors, which include occupational factors, contribute more to these inequalities than factors within the behavioral pathway, such as lifestyle (5). However, this review included only one study that assessed work factors. Another review also showed moderate evidence of a mediating effect of work factors on socioeconomic inequalities in health, which was operationalized as any objective or subjective health outcome, such as cardiovascular disease, disability pension, low back pain, and self-rated health (6). In addition to these reviews, our study provides more insight into (i) the evidence for the contribution of physical and psychosocial work factors to health inequalities and (ii) the importance of the contribution of work factors relative to the contribution of lifestyle factors. Our findings imply that the contribution of work factors to health inequalities might be larger than the contribution of lifestyle factors; in the five studies that estimated both the contribution of work and lifestyle factors $(35,37,38,42,46)$, the median contribution of work factors was two and a half times as high as the median contribution of lifestyle factors (54\% versus $21 \%)$. In addition, in all studies, work factors explained part of the health inequalities when models were adjusted for lifestyle factors $(16,38$, $39,41)$, while lifestyle explained only part of the health inequalities when models were adjusted for work factors in 1 of the 2 studies $(40,42)$. Overall, we conclude that work factors seem to be important contributors to socioeconomic inequalities in self-rated health irrespective of lifestyle behaviors. These findings further highlight that work and lifestyle factors are strongly intertwined, and should be analyzed together as the real contribution of work and lifestyle factors to health inequalities would otherwise be largely overestimated.

Despite strong evidence for the combined contribution of psychosocial and physical work factors to socioeconomic inequalities in self-rated health among workers, we observed no evidence for the separate influence of physical work factors on health inequalities in longitudinal studies. The 2 high-quality longitudinal studies showed no clear contribution $(<10 \%)$ of the combination of physical workload and physical work environment to socioeconomic inequalities in self-rated health among workers $(20,21)$. Of these, 1 study measured physical work factors with a simple question and analyzed the effect of physical workload and physical work environment on self-rated health after a mean follow-up of 23 years when the participants were already retired (20). Therefore, it is likely that other factors after retirement influenced self-rated health, and consequently physical work factors no longer substantially contributed to the health inequalities. In our sensitivity analyses, we also showed that the contribution of work factors to health inequalities was larger in the cross-sectional studies 
using more detailed measurements of work factors. The longitudinal study of Schmitz (21) measured work factors using a job exposure matrix, which does not take into account within-occupation differences. This method may have led to an underestimation of the true contribution of work factors to health inequalities. Thus, the absence of a contribution of work factors in those longitudinal studies may be due to the use of a too limited assessment of work factors. All cross-sectional studies indicate that physical work factors, such as repetitive movements, awkward postures, heavy lifting, or chemical exposures, contribute to socioeconomic inequalities in self-rated health. One of the possible mechanisms is that these physical work factors lead to musculoskeletal disorders (47), which can result in worse self-rated health (44). Considering the strong evidence from 3 longitudinal studies on the combined effect of physical and psychosocial work factors $(21,41,42)$ and the consistent direction of crosssectional studies, it seems plausible that physical work factors, in particular physical workload, contribute to the health inequalities. However, this needs to be confirmed in high-quality longitudinal studies.

Psychosocial work factors contributed to the socioeconomic differences in self-rated health among workers in 14 studies. Previous research shows that these psychosocial work factors increase the risk for mental health problems and stress-related disorders (48-50), which affects self-rated health negatively (51). An opposite effect of psychosocial work factors to socioeconomic inequalities in self-rated health was observed in 4 studies $(14,18,20,52)$; 1 of which used the demand-control model (53) to distinguish between different psychosocial work factors (52). This study found that job resources contributed to the health inequalities as workers with a low SES had less reward and less autonomy in their work than workers with a high SES, whereas a reverse effect was found for work demands, such as working overtime and job overload (52). This has been supported by other included studies that investigated part of the demand-control or the effort-reward imbalance models $(53,54)$. These studies found a reverse effect for the contribution of job demands $(16,17,22,23,35,52)$, and a contributing effect of job rewards (13), decision authority $(16)$, and job control $(17,22,23)$ to the health inequalities. Thus, it is likely that a lack of job resources contribute to socioeconomic health inequalities whereas most job demands do not.

The first strength of this review is the systematic approach by which the literature on the contribution of work and lifestyle factors to explaining the socioeconomic inequalities in self-rated health was summarized. Due to the extensive search string, the large number of articles screened on eligibility, and the reference list screening that did not lead to additional studies, it is unlikely that we missed relevant published studies. A study assessing psychosocial work factors was excluded after title and abstract screening because of the Spanish language (55). This study had a cross-sectional design, and would therefore not affect the conclusions. A limitation of this review is that we might have missed studies that were not published due to the absence of significant results. This might have led to an overestimation of the contribution of work and lifestyle factors to socioeconomic inequalities in self-rated health. Additionally, due to the heterogeneity in study designs, measurement of work and lifestyle factors, and assessment of SES in the included studies, it was not possible to perform a meta-analysis. In order to give quantitative insight in the contribution of work and lifestyle factors, median percentages with interquartile range of change in the OR between the models with and without adjustment for work or lifestyle factors were calculated. However, these percentages are probably an overestimation of the real contribution of work and lifestyle factors because this is a relatively crude method to investigate mediation effects that may not take confounding and interactions sufficiently into account. This method does not reflect the real complex causal pathways, which has only been investigated in detail in the cross-sectional study of Sacker et al (37) using path analysis. Furthermore, it should be noted that most studies included in the present review had a cross-sectional design. These studies give strong indications that work and lifestyle factors contribute to health inequalities, but causal inferences cannot be made. The best-evidence synthesis was for that reason mainly based on longitudinal studies. Finally, our finding that none of the included studies investigated moderating effects of lifestyle and work on health inequalities underlines the need for future studies to do so.

\section{Concluding remarks}

Our findings show that there is strong evidence that work and lifestyle factors partly explain socioeconomic inequalities in self-rated health among workers. Furthermore, the results indicate that the contribution of work factors to explaining these health inequalities might be larger than the contribution of lifestyle factors. These findings might have important implications for public and occupational health policy and the development of interventions. It emphasizes the importance to focus on work factors, besides lifestyle factors, in order to reduce socioeconomic inequalities in self-rated health. We found indications that the lack of some psychosocial work factors (ie, job resources) contribute to socioeconomic inequalities in self-rated health whereas other factors (ie, job demands) do not. Further longitudinal studies should be performed to determine which specific work factors contribute the most to explaining socioeconomic inequalities in self-rated health among workers. 


\section{Acknowledgements}

This research was funded by the Netherlands Organisation for Health Research and Development (ZonMw) (grant number: 531001409)

\section{Conflict of interest}

The authors declare no conflicts of interest.

\section{References}

1. McFadden E, Luben R, Bingham S, Wareham N, Kinmonth AL, Khaw KT. Does the association between self-rated health and mortality vary by social class? Soc Sci Med 2009;68(2):275-80. https://doi.org/10.1016/j. socscimed.2008.10.012.

2. Bauer GF, Huber CA, Jenny GJ, Muller F, Hammig O. Socioeconomic status, working conditions and self-rated health in Switzerland: explaining the gradient in men and women. Int J Public Health 2009;54(1):23-30. https://doi. org/10.1007/s00038-008-7077-2.

3. Read S, Grundy E, Foverskov E. Socio-economic position and subjective health and well-being among older people in Europe: a systematic narrative review. Aging Ment Health 2016;20(5):529-42. https://doi.org/10.1080/13607863.2015 .1023766 .

4. Statistics. Gezonde levensverwachting; opleidingsniveau [English: healthy life expactancy: educational level]. The Hague, The Netherlands, 2016.

5. Moor I, Spallek J, Richter M. Explaining socioeconomic inequalities in self-rated health: a systematic review of the relative contribution of material, psychosocial and behavioural factors. J Epidemiol Community Health 2017;71:565-75. https://doi.org/10.1136/jech-2016-207589.

6. Hoven H, Siegrist J. Work characteristics, socioeconomic position and health: a systematic review of mediation and moderation effects in prospective studies. Occup Environ Med 2013;70(9):663-9. https://doi.org/10.1136/ oemed-2012-101331.

7. Baron RM, Kenny DA. The moderator-mediator variable distinction in social psychological research: conceptual, strategic, and statistical considerations. J Pers Soc Psychol 1986;51(6):1173-82. https://doi.org/10.1037/00223514.51.6.1173.

8. Heikkilä K, Fransson EI, Nyberg ST, Zins M, Westerlund $\mathrm{H}$, Westerholm P, et al. Job strain and health-related lifestyle: findings from an individual-participant metaanalysis of 118,000 working adults. Am J Public Health 2013;103(11):2090-7. https://doi.org/10.2105/ AJPH.2012.301090.

9. Miranda H, Gore RJ, Boyer J, Nobrega S, Punnett L. Health
Behaviors and Overweight in Nursing Home Employees: Contribution of Workplace Stressors and Implications for Worksite Health Promotion. Scientific World Journal 2015:915359.

10. Latham K, Peek CW. Self-rated health and morbidity onset among late midlife U.S. adults. J Gerontol B Psychol Sci Soc Sci 2013;68(1):107-16. https://doi.org/10.1093/geronb/ gbs 104.

11. DeSalvo KB, Bloser N, Reynolds K, He J, Muntner P. Mortality prediction with a single general selfrated health question. A meta-analysis. J Gen Intern Med 2006;21(3):267-75. https://doi.org/10.1111/j.15251497.2005.00291.x.

12. Idler EL, Benyamini Y. Self-rated health and mortality: a review of twenty-seven community studies. J Health Soc Behav 1997;38(1):21-37. https://doi.org/10.2307/2955359.

13. Aldabe B, Anderson R, Lyly-Yrjanainen M, ParentThirion A, Vermeylen G, Kelleher CC, et al. Contribution of material, occupational, and psychosocial factors in the explanation of social inequalities in health in 28 countries in Europe. J Epidemiol Community Health 2011;65(12):112331. https://doi.org/10.1136/jech.2009.102517.

14. Hämmig $\mathrm{O}$, Bauer GF. The social gradient in work and health: a cross-sectional study exploring the relationship between working conditions and health inequalities. BMC Public Health 2013;13:1170. https://doi.org/10.1186/14712458-13-1170.

15. Hämmig O, Gutzwiller F, Kawachi I. The contribution of lifestyle and work factors to social inequalities in self-rated health among the employed population in Switzerland. Soc Sci Med 2014;121:74-84. https://doi.org/10.1016/j. socscimed.2014.09.041.

16. Hemström $\mathrm{O}$. Health inequalities by wage income in Sweden: The role of work environment. Soc Sci Med 2005;61(3):637-47. https://doi.org/10.1016/j. socscimed.2004.12.028.

17. Kaikkonen R, Rahkonen O, Lallukka T, Lahelma E. Physical and psychosocial working conditions as explanations for occupational class inequalities in self-rated health. Eur J Public Health 2009;19(5):458-63. https://doi.org/10.1093/ eurpub/ckp095.

18. Lahelma E, Martikainen P, Rahkonen O, Roos E, Saastamoinen P. Occupational class inequalities across key domains of health: Results from the Helsinki Health Study. Eur J Public Health 2005;15(5):504-10. https://doi. org/10.1093/eurpub/cki022.

19. Niedhammer I, Chastang JF, David S, Kelleher C. The contribution of occupational factors to social inequalities in health: Findings from the national French SUMER survey. Soc Sci Med 2008;67(11):1870-81. https://doi. org/10.1016/j.socscimed.2008.09.007.

20. Parker V, Andel R, Nilsen C, Kareholt I. The Association Between Mid-Life Socioeconomic Position and Health After RetirementExploring the Role of Working Conditions. J Aging Health 2013;25(5):863-81. https://doi. org/10.1177/0898264313492822. 
21. Schmitz LL. Do working conditions at older ages shape the health gradient? J Health Econ 2016;50:183-97. https://doi. org/10.1016/j.jhealeco.2016.10.002.

22. Schrijvers CT, van de Mheen HD, Stronks K, Mackenbach JP. Socioeconomic inequalities in health in the working population: the contribution of working conditions. Int $\mathrm{J}$ Epidemiol 1998;27(6):1011-8. https://doi.org/10.1093/ ije/27.6.1011.

23. Toch M, Bambra C, Lunau T, van der Wel KA, Witvliet MI, Dragano N, et al. All Part of the Job? The Contribution of the Psychosocial and Physical Work Environment to Health Inequalities in Europe and the European Health Divide. Int J Health Serv 2014;44(2):285-305. https://doi.org/10.2190/ HS.44.2.g

24. Murcia M, Chastang JF, Cohidon C, Niedhammer I, Grp SS Contribution of occupational factors to social inequalities in self-reported health among French employees. Int Arch Occup Environ Health 2013;86(5):541-52. https://doi. org/10.1007/s00420-012-0784-2.

25. Hayden JA, Cote P, Bombardier C. Evaluation of the quality of prognosis studies in systematic reviews. Ann Intern Med 2006;144(6):427-37. https://doi.org/10.7326/0003-4819144-6-200603210-00010.

26. Proper KI, Singh AS, van Mechelen W, Chinapaw MJ. Sedentary behaviors and health outcomes among adults: a systematic review of prospective studies. Am J Prev Med 2011;40(2):174-82. https://doi.org/10.1016/j. amepre.2010.10.015.

27. van Ekris E, Altenburg TM, Singh AS, Proper KI, Heymans MW, Chinapaw MJM. An evidence-update on the prospective relationship between childhood sedentary behaviour and biomedical health indicators: a systematic review and meta-analysis. Obes Rev 2016;17(9):833-49. https://doi.org/10.1111/obr.12426.

28. Lynch JW, Kaplan GA, Cohen RD, Tuomilehto J, Salonen JT. Do cardiovascular risk factors explain the relation between socioeconomic status, risk of all-cause mortality, cardiovascular mortality, and acute myocardial infarction? Am J Epidemiol 1996;144(10):934-42. https://doi. org/10.1093/oxfordjournals.aje.a008863.

29. Agaliotis M, Mackey MG, Jan S, Fransen M. Burden of reduced work productivity among people with chronic knee pain: a systematic review. Occup Environ Med 2014;71(9):651-9. https://doi.org/10.1136/ oemed-2013-101997.

30. Kuijpers T, van der Windt DAWM, van der Heijden GJMG, Bouter LM. Systematic review of prognostic cohort studies on shoulder disorders. Pain 2004;109(3):420-1. https://doi. org/10.1016/j.pain.2004.02.017.

31. Twisk J. Inleiding in de toegepaste biostatistiek. Amsterdam: Reed Business Education; 2014.

32. Maldonado G, Greenland S. Simulation study of confounderselection strategies. Am J Epidemiol 1993;138(11):923-36. https://doi.org/10.1093/oxfordjournals.aje.a116813.

33. Geyer S, Hemstrom O, Peter R, Vagero D. Education, income, and occupational class cannot be used interchangeably in social epidemiology. Empirical evidence against a common practice. J Epidemiol Community Health 2006;60(9):804 10. https://doi.org/10.1136/jech.2005.041319.

34. Ferrie JE, Shipley MJ, Stansfeld SA, Smith GD, Marmot M, Whitehall IIS. Future uncertainty and socioeconomic inequalities in health: the Whitehall II study. Soc Sci Med 2003;57(4):637-46. https://doi.org/10.1016/S02779536(02)00406-9.

35. Mustard CA, Vermeulen M, Lavis JN. Is position in the occupational hierarchy a determinant of decline in perceived health status? Soc Sci Med 2003;57(12):2291-303. https:// doi.org/10.1016/j.socscimed.2003.08.001.

36. Dragano N, Wahrendorf M, Muller K, Lunau T. Work and health inequalities. The unequal distribution of exposures at work in Germany and Europe. Bundesgesundheitsblatt Gesundheitsforschung Gesundheitsschutz 2016;59(2):21727. https://doi.org/10.1007/s00103-015-2281-8.

37. Sacker A, Bartley M, Firth D, Fitzpatrick R. Dimensions of social inequality in the health of women in England: occupational, material and behavioural pathways. Soc Sci Med 2001;52(5):763-81. https://doi.org/10.1016/S02779536(00)00176-3.

38. Brand JE, Warren JR, Carayon P, Hoonakker P. Do job characteristics mediate the relationship between SES and health? Evidence from sibling models. Soc Sci Res 2007;36(1):222-53. https://doi.org/10.1016/j. ssresearch.2005.11.004.

39. Warren JR, Hoonakker P, Carayon P, Brand J. Job characteristics as mediators in SES-health relationships. Soc Sci Med 2004;59(7):1367-78. https://doi.org/10.1016/j. socscimed.2004.01.035.

40. Aittomäki A, Martikainen P, Laaksonen M, Lahelma E, Rahkonen O. The associations of household wealth and income with self-rated health--a study on economic advantage in middle-aged Finnish men and women. Soc Sci Med 2010;71(5):1018-26. https://doi.org/10.1016/j. socscimed.2010.05.040.

41. Warren JR, Carayon P, Hoonakker P. Changes in Health Between Ages 54 and 65 The Role of Job Characteristics and Socioeconomic Status. Res Aging 2008;30(6):672-700. https://doi.org/10.1177/0164027508322639.

42. Borg V, Kristensen TS. Social class and self-rated health: can the gradient be explained by differences in life style or work environment? Soc Sci Med 2000;51(7):1019-30. https://doi.org/10.1016/S0277-9536(00)00011-3.

43. Borrell C, Muntaner C, Benach J, Artazcoz L. Social class and self-reported health status among men and women: what is the role of work organisation, household material standards and household labour? Soc Sci Med 2004;58(10):1869-87. https://doi.org/10.1016/S02779536(03)00408-8.

44. Aittomäki A, Lahelma E, Rahkonen O, Leino-Arjas $\mathrm{P}$, Martikainen P. The contribution of musculoskeletal disorders and physical workload to socioeconomic inequalities in health. Eur J Public Health 2007;17(2):145- 
50. https://doi.org/10.1093/eurpub/ck1121.

45. Rahkonen O, Laaksonen M, Martikainen P, Roos E, Lahelma E. Job control, job demands, or social class? The impact of working conditions on the relation between social class and health. J Epidemiol Community Health 2006;60(1):50-4. https://doi.org/10.1136/jech.2005.035758.

46. Karmakar SD, Breslin FC. The role of educational level and job characteristics on the health of young adults. Soc Sci Med 2008;66(9):2011-22. https://doi.org/10.1016/j. socscimed.2008.01.017.

47. da Costa BR, Vieira ER. Risk factors for work-related musculoskeletal disorders: A systematic review of recent longitudinal studies. Am J Ind Med 2010;53(3):285-323.

48. Stansfeld S, Candy B. Psychosocial work environment and mental health - a meta-analytic review. Scand J Work Environ Health 2006;32(6):443-62. https://doi.org/10.5271/ sjweh. 1050 .

49. Nieuwenhuijsen K, Bruinvels D, Frings-Dresen M. Psychosocial work environment and stress-related disorders, a systematic review. Occup Med (Lond) 2010;60(4):277-86. https://doi.org/10.1093/occmed/kqq081.

50. Theorell T, Hammarstrom A, Aronsson G, Traskman Bendz L, Grape T, Hogstedt C, et al. A systematic review including meta-analysis of work environment and depressive symptoms. BMC Public Health 2015;15:738. https:/doi. org/10.1186/s12889-015-1954-4.
51. Ocampo-Chaparro JM, Zapata-Ossa HD, Cubides-Munevar AM, Curcio CL, Villegas JD, Reyes-Ortiz CA. Prevalence of poor self-rated health and associated risk factors among older adults in Cali, Colombia. Colombia Medica 2013;44(4):224-31.

52. Qiu H, Bures R, Shehan CL. The inconsistent mediating effects of psychosocial work characteristics on the educationhealth relationship. Soc Sci Med 2012;75(8):1539-46. https://doi.org/10.1016/j.socscimed.2012.06.008.

53. Karasek RA. Job Demands, Job Decision Latitude, and Mental Strain - Implications for Job Redesign. Admin Sci Quart 1979;24(2):285-308. https://doi. org/10.2307/2392498.

54. Siegrist J. Adverse health effects of high-effort/low-reward conditions. J Occup Health Psychol 1996;1(1):27-41. https://doi.org/10.1037/1076-8998.1.1.27.

55. Rocha KB, Muntaner C, Solar O, Borrell C, Bernales $\mathrm{P}$, Gonzalez MJ, et al. Social class, psychosocial occupational risk factors, and the association with selfrated health and mental health in Chile. Cad Saude Publica 2014;30(10):2219-34. https://doi.org/10.1590/0102$311 \times 00176213$

Received for publication: 22 March 2018 